\title{
A Study of Finding the Reasons of not Choosing Mathematics at Senior Secondary Level by Girls in Nawada District of Bihar
}

\author{
Marufa Gulnaz ${ }^{1 *}$, Roohi Fatima ${ }^{1}$ \\ ${ }^{1}$ Department of Teacher's Training and Non Formal Education, LASE, Faculty of Education, Jamia Millia Islamia, New \\ Delhi, INDIA
}

*Corresponding Author: marufagulnaz@gmail.com

Citation: Gulnaz, M. and Fatima, R. (2019). A Study of Finding the Reasons of not Choosing Mathematics at Senior Secondary Level by Girls in Nawada District of Bihar. Pedagogical Research, 4(4), em0043. https://doi.org/10.29333/pr/5899

Published: August 29, 2019

\begin{abstract}
Mathematics has an essential part of our life. In any environment, we are using it without any consideration. Mathematics teaches the equity and equality principle of democracy, in which all human being are equal for perceiving mathematics. The participation of female students in mathematics related field is least, as we say that female are backward in mathematics. So the researcher planned to finding out the reason behind the less interested and less participation of girls in math and its related field. She used self questionnaire for conducting the research among 80 girls of private and government students of Nawada district of Bihar state, India. And finds out that Most of the students started disliking mathematics when they were in their junior secondary classes and making responsible herself and teaching and learning method.hey also wants to learn mathematics again under the condition of good teaching and starts from basic. Students also suggest that subjects are dividing between the sexes no particular field is separated for particular sex. Girls who have interest in any field can choose and go and make their career.
\end{abstract}

Keywords: mathematics, senior secondary school interest in mathematics, mathematics chapter

\section{INTRODUCTION}

Mathematics has played a decisive role in building up our civilization and therefore, it has become essential for the existence and progress of modern world. In today's world we have to exact in our expression and so we make larger use of quantitative methods. . Mathematics has not been useful in its own right but it has also enriched this world by helping in development of other fields of knowledge. It exhibits the power to think consistently and logically. It helps in our quest in knowledge, truth beauty desire to interpret and control our environment. Through mathematisation, the culture is adopting and transferring throughout the world.

Kothari commission (1964-66) known as Indian education commission has pointed out:

\footnotetext{
"We cannot overstress the importance of mathematics in relation to science, education and research. This has always been so, but at no time has the significance of mathematics been greater than today ...... It is important that deliberate effort is made to place India on the 'world map of mathematics' within the next two decades so".
}

Knowledge of mathematics is essential for all members of our society. To participate fully in democratic processes and to be unrestricted in career choice and advancement, people must be able to understand and apply mathematical ideas (Stanic, 1988). 
In addition, from a human rights and democratic perspective, all should have equal rights and have equal opportunities, including studying and working in the field of their choice. Men and women have the equal right to choose subject for studying and building their career. But the significant difference between gender and subjects seen in our environment, in a study of Chad Topaz Professor in the Mathematics department at Macalester College, St. Paul, MN, he recognize that his field had a gender problem. In mathematics department, just $15 \%$ of the whole population are women, $18 \%$ of the population of sciences, along with computer science and $14 \%$ in engineering are covered by women. But Social sciences and natural science have more than or in equal ratio covered by women. In Social science like in psychology (55\%) and Natural science like biology $(34 \%)$ has women population (Hu, 2016).

Above study says that mathematics and its related field (engineering, computer science etc.) Have lowest rate of women participation while social science and biology field have more than or equal participation. So the researcher wants to conduct a study about the finding out the reasons of lowest participation of girls in mathematics and its related field.

\section{REVIEW OF RELATED LITERATURE}

- Samuelsson and Samuelsson (2016) discuss on two major objectives, 'gender differences between boys and girls in their perception of the classroom setting' and 'perception of classroom settings in relation to achievement in mathematics and aspects of self-regulated learning skills'. They find out from first objective boys felt that they were more invited to influence their work conditions than girls, and they felt that mathematics learning contained a greater portion of group work than girls. There is a significant difference between how boys and girls perceive their relationship to mathematics with respect to the importance of the subject and its difficulty. And another objectives find out a supportive group environment for girls seemed to predict high grades in math in a greater way than a supportive group environment for boys. Participation, as well as properly communicated objectives affected girls' achievement in a more positive way than boys. Boys were more sensitive to great demands and group work than girls were.

- Nuthanap (2007) focused on academic achievement among high school students and study habits of boys and girls. Majority of boys and girls belonged to the category of excellent academic achievement and significant association was found between academic achievement with boys and girls. There was no difference between boys' and girls' academic achievement. The socio economic status of the family had significant influence on the academic achievement of the boys and girls. There was significant difference of boys and girls between rural and urban students with respect to academic achievement. There was no association between boys and girls on study habits. Boys and girls do not differ significantly on overall study habits. But they differed significantly on two dimensions of reading \& note taking habits \& preparation for examination. 8th, 9th and 10th standard students differed significantly on study habits.

- Amelink (2012) stated that Lack of interest in mathematics has direct implications for student involvement in areas that require a strong math background, including science, technology, engineering and mathematics (STEM) discipline subject and careers, particularly for females. Lower interest is closely related to lower performance on math-related achievement tests and lower grades in math and this is challenging for mathematics enrollment in college. Females express less interest in mathematics than male peers.

- Frenzel et al. (2007) conducted a research to study gender differences in achievement emotions in the domain of mathematics. Findings suggested that the female emotional pattern was due to the girls' low competence beliefs and domain value of mathematics, combined with their high subjective values of achievement in mathematics. Multiple-group comparisons confirmed that the structural relationships between variables were largely invariant across the genders.

\section{NEED OF THE STUDY}

Based on her experience the researcher had observed in her 11 th science (Mathematics) class that there were 30 students and of those students, only 3-4 girls. She also observed in her under graduation \{B.Sc. (Mathematics)\} that the strength of the class was 130 and out of them only 10 were girls. It does not mean that girls are backward in education while girls have a great contribution in education in present scenario than past. Thus, this is the topic seems to be discussed: what are the reasons behind this great difference between girls and boys in studying Mathematics? Thus, the purpose of the present study is to identify the reason behind "girls not choosing mathematics in their mathematics subject in their senior secondary education in Nawada district of Bihar". 


\section{METHODOLOGY}

The present study aims together in depth study of the reasons for not choosing mathematics by the girl students at senior secondary level of Nawada district of Bihar state. It lies for the realm of Qualitative research. Therefore, the survey research method has been adopted for this study. This study examines the perception and a view of girl students towards Mathematics as well as it is used to gain the understanding of underlying reasons, opinion and motivation towards mathematics. This study randomly assigned 6 senior secondary school 3 private and 3 government) and select randomly 80 girl students of first and second year senior secondary class of the same district. For conducting survey the questionnaire tool consists 19 questions of both open ended and closed ended form had been used. The questionnaires had been prepared under the four major objectives; (a) To study the views of girl student about Mathematics. (b) To study the reasons behind for not choosing Mathematics in their senior secondary school. (c) To study the perception of girl's students regarding some common notion related to mathematics. (d) To study the parents and girls students opinionnaires regarding their career and future prospects.

\section{INTERPRETATION OF RESULTS}

\section{Objective 1: To Study the Views of Girl Student about Mathematics}

\section{Item 1: Responses about interested and not interested in mathematics}

From the responses the researcher revealed that more than half of the respondents $(56.25 \%)$ are interested in mathematics. Because it gives them inner happiness, enhance thinking ability, improve creative thinking and it gives an opportunity to use their own thinking. Some responds that they are interested in mathematics but realize that it is a hard and difficult subject. And some responds than they are interested in mathematics but less than their favorite subjects (biology, social science etc). While less than half of the respondents (43.75\%) are not interested in mathematics. Because it is much more tough and difficult subject. It takes more time while calculation, in a single mistake whole answer would be wrong. Some students making responsible of not interesting in mathematics is, "teacher and teaching", A student claims that those who is good in this particular subject or sit in front of teacher, teacher teach them well, those who sit in back seat or weak in math, teacher shows less interest to teach them, and teacher also not teach well, bad condition of teaching and study. Some student responds that Mathematical formula, concepts, logics are creating confusion, they always forget formula and also include that mathematics is "complicated" and "a depression device".
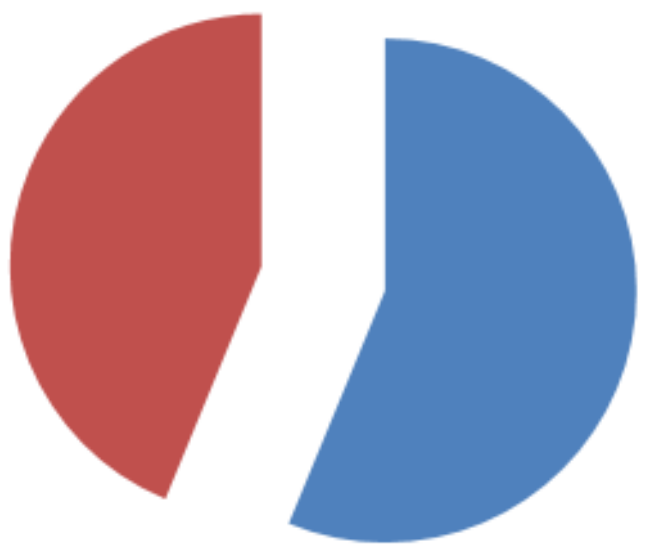

\section{Interested in} Mathematics

\section{Not Interested}

Figure 1. Responses about interested and not interested in Mathematics 


\section{Item 2: Thoughts about mathematics}

Responses revealed that less than half of the respondents (40\%) said that mathematics is good subject. Less than one fourth of the respondents $(23.75 \%)$ said that it is an interesting game. It develops our mind, create critical thinking, increase logical ability, gives the energy to think and understand, refresh the mind, play with mind etc. again less than half of the respondents $(21.25 \%)$ said that it is a hard subject", more formulas for remember. some students responds that it is A HORRIBLE AND DANGEROUS SUBJECT.

\section{Good subject}

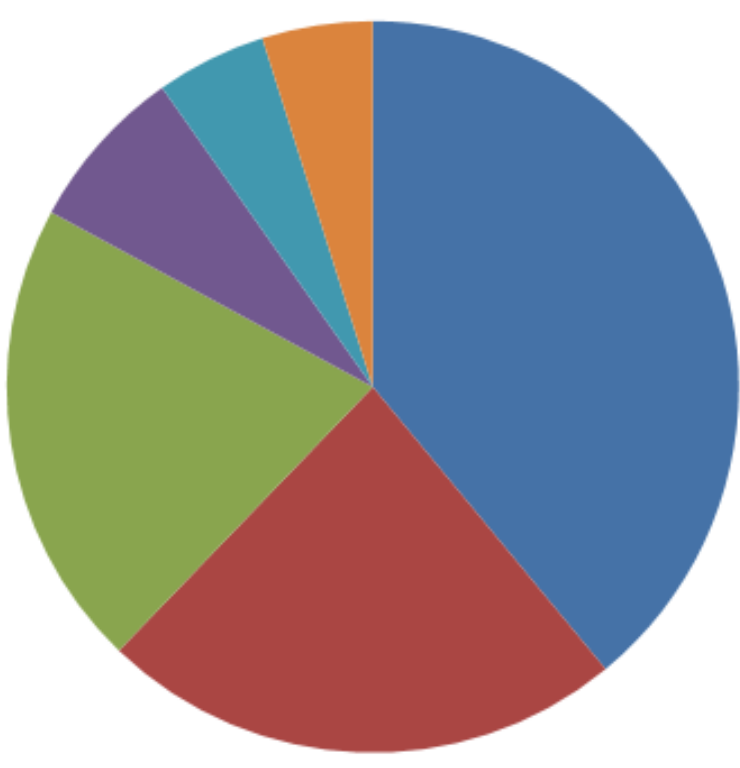

Figure 2. Thoughts about mathematics

\section{Interesting game}

\author{
A hard subject
}

- Important and usefull everyone to study Others

\section{A horrible and dangerous subject}

\section{Item 3: Decision about studying mathematics again}

Responses revealed that less than three forth of the respondents $(70 \%)$ said that if the opportunity will be provide for studying mathematics again but under certain condition, if teacher teach them well and starts with basics. While more than one fourth of the respondents (30\%) said that they do not wish for studying math again.

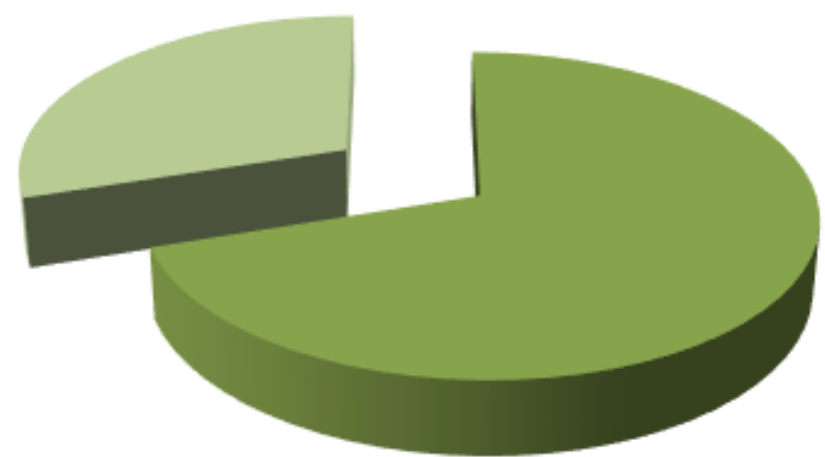

\section{Positive response negative response}

Figure 3. Decision about studying mathematics again

\section{Item 4: Likeness of mathematics chapter on their previous class}

Responses revealed that one fourth of the respondents $(25 \%)$ said that they like trigonometry chapter of mathematics and some respondents $(6.25 \%)$ said that they like all chapters of mathematics, and other student responds that they like other chapters of mathematics as mentioned below. 
Pedagogical Research, 4(4), em0043

Table 1. Likeness of mathematics chapter on their previous class

\begin{tabular}{ll}
\hline Chapter & No of Students Likeness \\
\hline Trigonometry & 20 \\
\hline Not Fill & 6 \\
\hline All Chapters & 5 \\
\hline Probability & 5 \\
\hline Statistics & 5 \\
\hline Volume, Area & 5 \\
\hline Construction & 3 \\
\hline Geometry & 3 \\
\hline Algebra & 2 \\
\hline Arithmetic Progress & 2 \\
\hline Compound Interest & 2 \\
\hline Graph, Bar & 2 \\
\hline Others & 2 \\
\hline Probability, Construction & 2 \\
\hline Problems Based On Logical Thinking & 2 \\
\hline Quadratic Equation & 2 \\
\hline Triangle & 2 \\
\hline Algebra, Graph & 1 \\
\hline Arithmetic Progress, Probability & 1 \\
\hline Calculation & 1 \\
\hline Construction, Geometry & 1 \\
\hline Fraction & 1 \\
\hline Linear Equation & 1 \\
\hline No Chapters & 1 \\
\hline Probability, Statistics & 1 \\
\hline Set & 1 \\
\hline Shaded Region & 1 \\
\hline
\end{tabular}

\section{Item 5: Dislike of mathematics chapters}

Responses revealed that most of the respondents said that they do not like Algebra \& trigonometry chapters of mathematics. And other respondents unlike other chapters of mathematics as mentioned below.

Table 2. Dislike of mathematics chapters

\begin{tabular}{ll}
\hline Chapter & No of Students \\
\hline Algebra & 11 \\
\hline Not Fill & 11 \\
\hline Trigonometry & 10 \\
\hline Mensuration & 6 \\
\hline Area, Volume & 5 \\
\hline No Chapter & 5 \\
\hline Probability & 4 \\
\hline Geometry & 3 \\
\hline All Most All & 2 \\
\hline Angle & 2 \\
\hline Binomial & 2 \\
\hline Pythagoras & 2 \\
\hline Theorem Part & 2 \\
\hline Arithmetic & 1 \\
\hline Arithmetic Progress & 1 \\
\hline Calculation & 1 \\
\hline Compound Interest & 1 \\
\hline Graph & 1 \\
\hline Mensuration, Calculation & 1 \\
\hline Mensuration, Trigonometry & 1 \\
\hline Quadrilateral & 1 \\
\hline Statistics & 1 \\
\hline
\end{tabular}




\section{Item 6: Responses of ever enjoying mathematics class}

Responses revealed that more than three forth of the respondents (80\%) said that they enjoyed their mathematics class. When they were in $9^{\text {th, }} 10^{\text {th }}$, Till 7 th, 8 th class, in tuition, in some interesting chapters (trigonometry, probability, construction etc.) while less than one fourth of the respondents (20\%) said that they never enjoyed mathematics class.

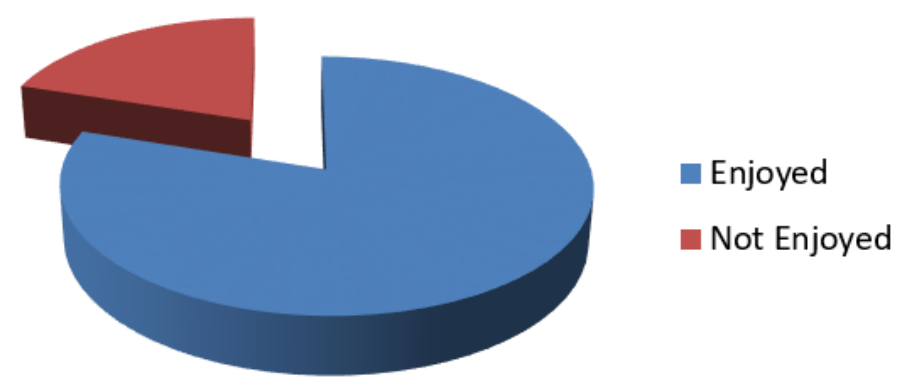

Figure 4. Responses of ever enjoying mathematics class

\section{Item 7: Class from which started disliking mathematics}

Responses revealed that more than one fourth of the respondents $(26.25 \%)$ said that they never dislike mathematics. And more than one fourth of the respondents $(26.25 \%)$ said that they were started disliking mathematics when they were in $9^{\text {th }}$ class. less than one fourth of the respondents $(20 \%)$ said that they were, started disliking mathematics when they were in $10^{\text {th }}$ class. And many of other respondents said that they were other class that they started disliking from $11^{\text {th }}, 7^{\text {th }}, 8^{\text {th }}, 6^{\text {th }}$ and 5 th class.

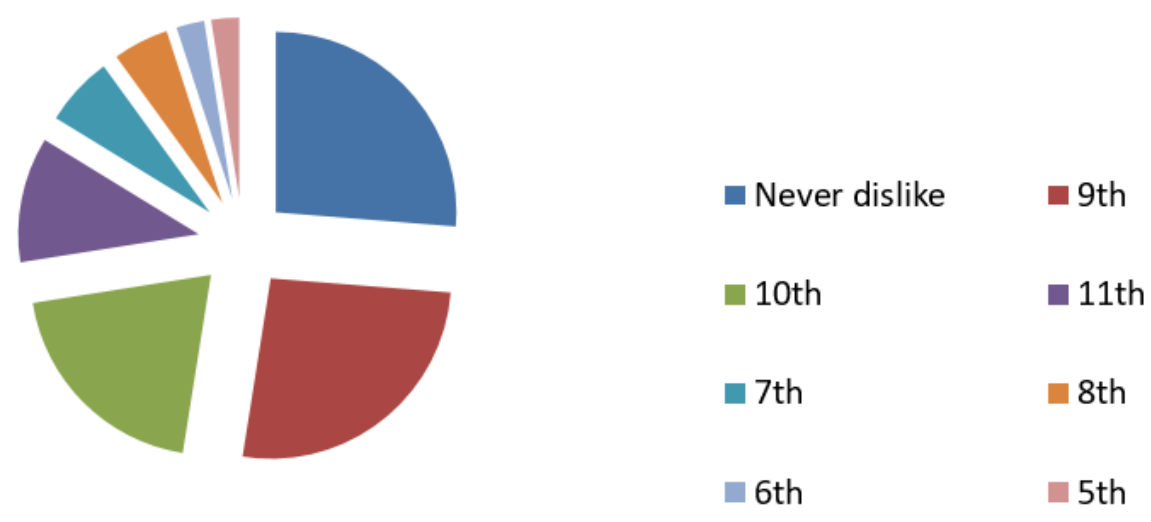

Figure 5. Class from which started disliking mathematics

\section{Item 8: Feeling discrimination in their mathematics class or by class teacher}

Responses revealed that more than half of the respondent (65\%) said that they were never feel discrimination by their teacher or by their classmates in their mathematics class room. and more than one fourth of the respondents $(30 \%)$ said that they feel discrimination by their teacher or by their classmates in their mathematics classroom.

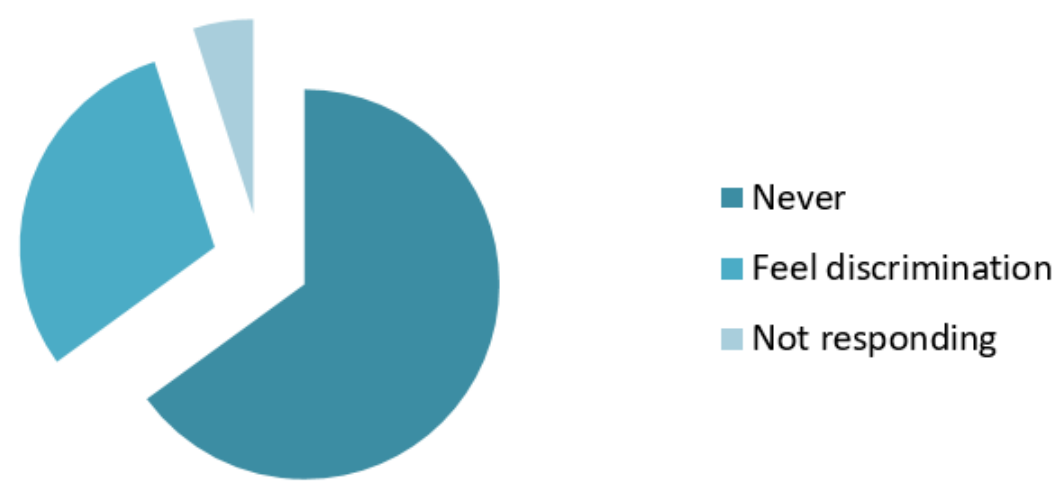

Figure 6. Feeling discrimination in their mathematics class or by class teacher 


\title{
Item 9: Responsible for disliking mathematics
}

Responses revealed that approximately three forth of the respondents $(72.5 \%)$ said that they were making responsible herself for disliking mathematics, some making other responsible as teacher, teaching, book, classmates, parents etc.
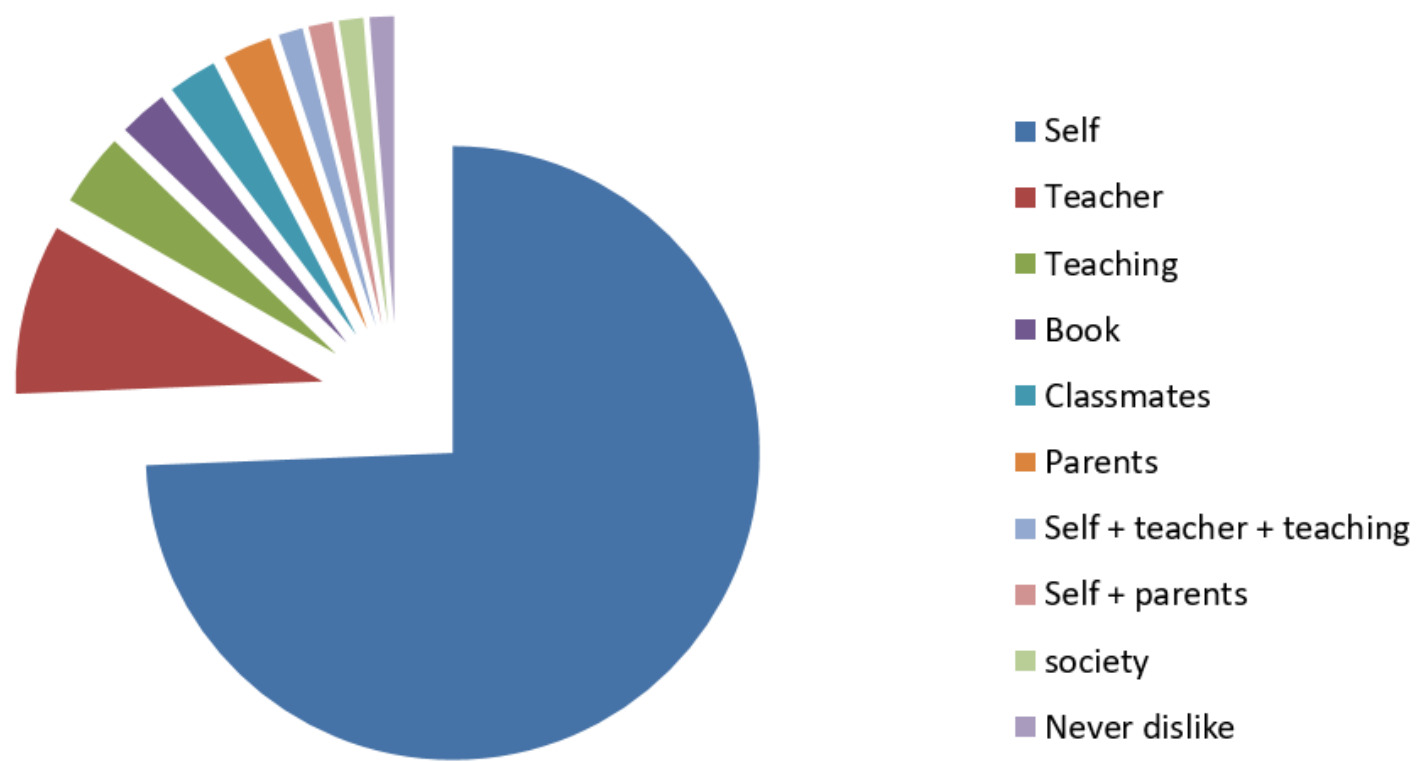

Figure 7. Responsible for disliking mathematics

Objective 2: To Study the Reasons behind for not Choosing Mathematics in their Senior Secondary School

\section{Item 10: Reasons behind not selecting mathematics in their senior secondary class}

Responses revealed that more than one fourth of the respondents $(38.75 \%)$ were not interested in math. Approximately one fourth of the respondents $(22.5 \%)$ were interested in their chooses subject like Science (Biology), Arts (Social Science, Political Science), Commerce (Accounts) than Mathematics .. less than one fourth of the respondents $(18.75 \%$ ) said that they were wish to go to medical field or aim to become a doctor. Rest of the Respondents have other reasons like "subject was not available in our school/locality and if available", “ inadequacy of math teacher", "Regular class was compulsory for math", " not get good marks ever in math and it will affect other subject", "Due to poverty gave-up math choice", "Friends didn't take math" etc.

\section{Item 11: Responsible for not choosing mathematics: parents/self}

Responses revealed that approximately three forth of the respondents $(72.5 \%)$ said that it was their own decision for not opting mathematics in their senior secondary class. Less than one fourth of the respondents $(11.25 \%)$ said that student and parents both were involve for deciding for not opting mathematics at their senior secondary level class.

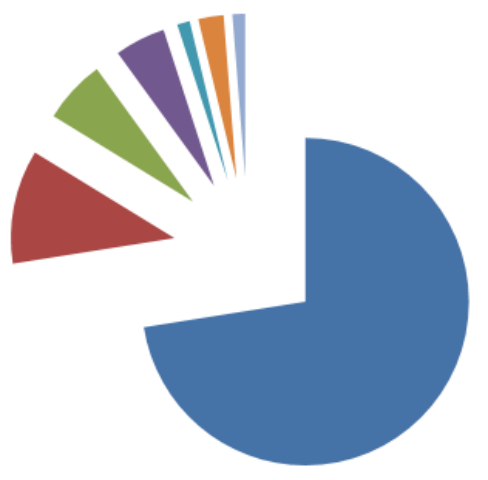

\author{
students own choice \\ Both students and parents choice \\ घtudent choose against parents wish \\ parents choice \\ students wish for math but family forced for biology \\ Not give answer \\ cause of friend's company
}

Figure 8. Parents/self: responsible for not choosing mathematics 


\section{Item 12: Class of deciding for opting their particular subject other than mathematics in their senior secondary class}

Responses revealed that approximately half of the respondents $(48.75 \%)$ were decided for their opted subjects (Biology, commerce, Arts etc.) during and after secondary class. less than one fourth of the respondents (16.25\%) were decided in their $9^{\text {th }}$ class. less than one fourth of the respondents $(11.25 \%)$ were decided in their elementary class like $8^{\text {th }}, 7$ th, 5 th, 3rd, and since childhood. And rest of the respondents has decided in other occasion like 'inspired by relative to become doctor', 'suddenly on admission time', 'unavailability of seats in math' etc.

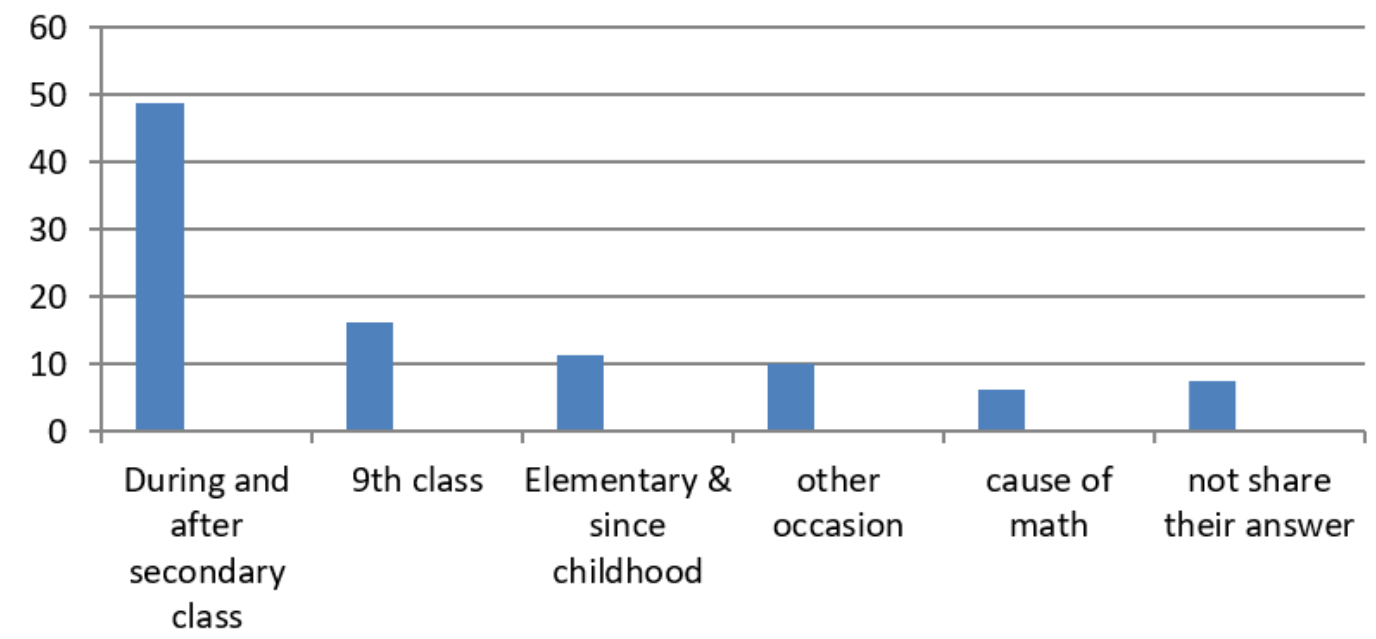

Figure 9. Decision of decision opting particular subject

\section{Item 13: Incidents happen that encourage for not selecting mathematics}

Responses revealed that more than half of the respondents (56.25\%) said that there was no incident happened with them which influence their decision of not choosing mathematics. less than half of the respondents $(41.25 \%)$ said that there was incident happened with them which influence them that they were not choose mathematics in future. their incidents were 'got less marks in junior class', 'In 10th class test taken by father in math and fail to solve, then father was angry and scolded', 'many times it was taken more time to solve', 'failed continuously 3 years in math' etc.

Objective 3: To Study the Perception of Girl's Students regarding some Common Notion related to Mathematics

\section{Item 14: Responses regarding teacher's statement "mathematics is not for girls"}

Responses revealed that more than three forth of the respondents $(82.5 \%)$ said that they had never listened "Mathematics is not for girls" in their class by teacher. Less than one fourth of the respondents $(15 \%)$ said that they had listened this type of statement in their class. Some said not by teacher but in society and home people said "Math ladkiyoun ke liye jaroori nabin h, shaddi ke baad to sasural hi jana h, aur chulha chauka hi karna hai.

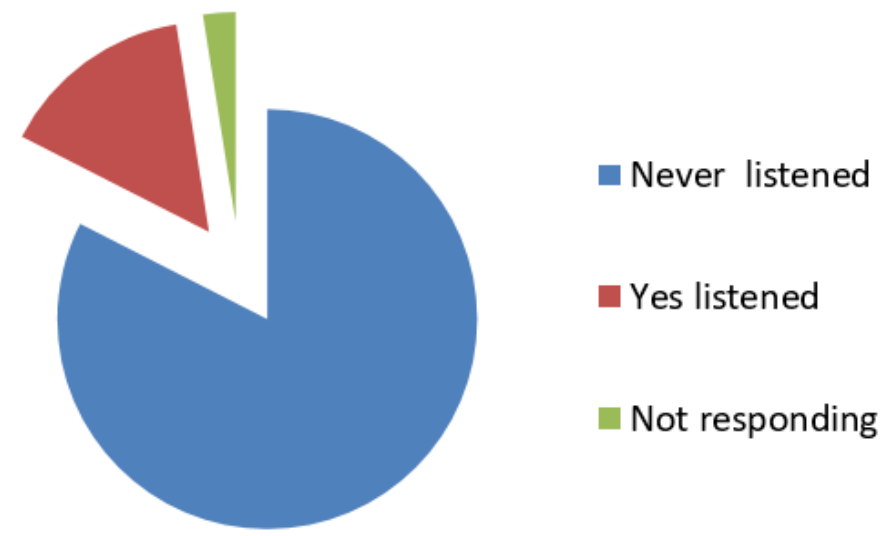

Figure 10. Responses regarding teacher's statement "mathematics is not for girls" 
Item 15: Responses regarding the statement mathematics is more useful for boys in future, as boys opt more for sciences and engineering for career

Responses revealed that different students give different responses about "Mathematics is more useful for boys in future, as boys opt more for Sciences and Engineering for career" It is only a mentality, 'It is depend upon labor not depend upon boys or girls', 'Boys interested in mathematics', 'A narrow minded mentality', 'Yes, math is important for mostly for boys for engineering', 'It is only boys thought that math have many scope', 'A mistake, even if math or biology girls are better', 'Engineering in India is worst cause of math's preference', 'Girls also select engineering' etc.

\title{
Item 16: Responses about "girls have the lower rate in mathematics related field"
}

Responses revealed that more than one fourth of the respondents (40\%) that they gave the causes of the statement "Girls have the lower rate in mathematics related field" as mathematics is difficult subject, girls are weak in math and they are not interested in mathematics so they are less in mathematics and its related field. less than one fourth of the respondents $(20 \%)$ said that girls are already interested in other field like Medical, Biology, Arts, Management, Fashion Designer etc. so they are less number in this particular subject related field. More than one fourth of the respondents (36.25\%) gave other causes as 'parents force for biology', 'it is society mentality', 'Boys go out to study with good teacher, but girls no do so', 'Girls focus their mind on all things except math', 'Girls have to do domestic work; they have no time for studying', 'Cause of child marriage they have dropout', 'Unavailability of teacher in school in mathematics subject', 'Parent's does not give permission for studying after secondary class' etc.

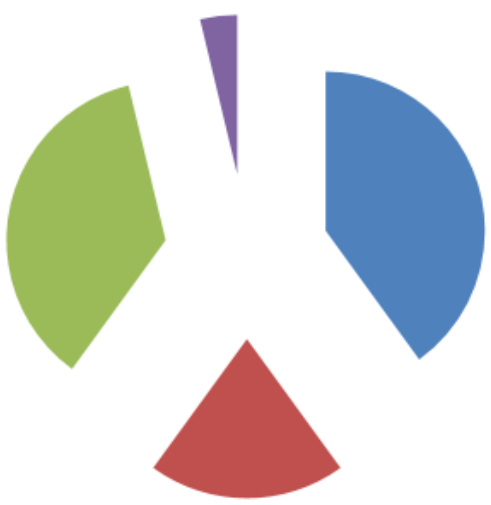

\author{
- Cause of mathmatics \\ diffculty weak and not \\ interested \\ - Interested in other \\ subject \\ other reasons \\ Not agree about this \\ statement
}

Figure 11. Responses about "girls have the lower rate in mathematics related field"

\section{Item 17: Responses regarding competitive exams based on mathematical problems should be taken or not}

Responses revealed that less than three forth of the respondents (70\%) said YES it should be conducted that type of competitive exams which is based on mathematical problems, because if it will not done girls will have negligible interest in mathematics, It makes mentality strong, Math is daily life subject, it increases logical thinking, mostly girls take biology and fully give-up math, math solves by mind and examiner sees the mind etc. More than one fourth of the respondents $(27.5 \%)$ said NO it should not be conducted because those exams should contain all subjects, exams should be based on own subject, those who don't understand leave the question.

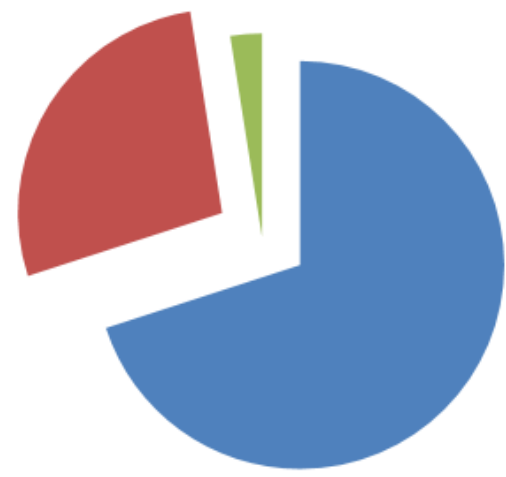

\author{
Yes it should be \\ conducted \\ NO it should not be \\ conducted \\ Does not give any \\ responses
}

Figure 12. Responses on competitive exams based on mathematical problems 
Objective 4: To Study the Parents and Girl Student's Opinionnaires regarding their Career and Future Prospects

Item 6 and 20 were designed to study the objective of opinion of parents and girls students regarding their career and future prospects.

\section{Item 18: Parents expectations with girl's student career}

Responses revealed that more than one fourth of the respondents $(31.25 \%)$ said that their parents expectation with them about their career were "do something in life", "Spread your name \&your father name", "Become something with education "no one is educated at home", "Teach others that they go ahead" etc. less than one fourth of the respondents $(22.5 \%)$ said that their parents wish to be good and successful Doctor. A few respondents $(5 \%)$ said that their Parents wish to see their daughter an I.P.S Officer, C.I.D Officer, Professor etc. some respondents $(10 \%)$ said that their Parents have not big expectation like doctor or an officer but a social welfare thought as Be a good citizen", "A successful person", "Achieve good place", "Teach other that they go ahead", "Get good education", "Self reliance", "Self depend etc. less than one half of the respondents (16.25\%) said that their father had neither big expectations nor social welfare thought but had other expectations as "No break in study", "Become something, but parents don't have money", "No wishes only B.A pass", "Get good degree\& get marry in good family" etc.

\section{Item 19: Responses regarding best field for girls for their career}

Responses revealed that more than one fourth of the respondents $(26.25 \%)$ said that every field in which girls have interest is best for them. No particular or separated field is proper and suitable for them. Every field is best field for them for making career. Less than one fourth of the respondents $(17.5 \%)$ said that Doctor\& Medical field is best for girls. Other students have other suggestion as like Army, Police, Teacher, Engineering, I.P.S, I.A.S, Math's related field, Biology field, Bank, Lawyer, Judge, Doctor, Fashion designer etc.

\section{MAJOR FINDINGS OF THIS STUDY}

1. Most of the students are interested in mathematics but they also interested in their favorite or elected subjects (biology, social science etc) more than mathematics and some realize mathematics is hard and tough subject so, they can't choose mathematics in their senior secondary class.

2. Most of the students reveal that mathematics is an interesting game, which develops our mind, create critical thinking, increase logical ability, gives the energy to think and understand, refresh the mind, play with mind etc.

3. Most of the students want to study mathematics again, if teacher teach them well and starts with basics.

4. Subject should not be divided between sexes.

5. Some student reveals that those who is good in this particular subject or sit in front of teacher, teacher teach them well, those who sit in back seat or weak in math, teacher shows less interest to teach them.

6. In schools bad condition of teaching and learning are the main cause of less interest in mathematics.

7. Most of the students liked TRIGONOMETRY chapter in their previous class.

8. Most of the students started disliking mathematics when they were in $9^{\text {th }}$ or $10^{\text {th }}$ class.

9. Most of the students making responsible oneself for disliking mathematics and not selecting mathematics stream in their Senior Secondary class and they take this decision in during and after secondary and in $9^{\text {th }}$ class.

10. Students revealed that they listened in thier society that "Math ladkiyoun ke liye jaroori nabin h, shaddi ke baad to sasural hi jana h, aur chulha chanka hi karna hai.

11. The competitive exam which is based on mathematical problems should be conducted because it makes mentality strong, it increases logical thinking, if it will not done girls will have negligible interest in mathematics.

12. Most of the parents have professional expectations that their daughter will become an I.P.S Officer, C.I.D Officer, doctor, Professor etc.

13. Some parents have social welfare thought that their daughter will Be a good citizen", "A successful person", "Achieve good place", "Teach other that they go ahead", "Get good education", "Self reliance", "Self depend etc.

14. Most of the students recommend that every field in which girls have interest is best for them for making career. No particular field is divided for particular sex. 


\section{SUMMARY}

Mathematics has an essential part of our life. In any environment, we are using it without any consideration. Mathematics develops logical and critical thinking in human being and logical and critical thinking are an essential part of existence and progress of modern world.

Kothari commission (1964-66) known as Indian education commission has pointed out:

"We cannot overstress the importance of mathematics in relation to science, education and research. This has always been so, but at no time has the significance of mathematics been greater than today ....... It is important that deliberate effort is made to place India on the 'world map of mathematics' within the next two decades so".

Mathematics teaches the equity and equality principle of democracy, in which all human being are equal for perceiving mathematics. However, in recent decades there is no equality of subject choice whereas male choose engineering mathematics and female select social science humanities and biology as above mentioned. The participation of female students in mathematics related field is least, as we say that female are backward in mathematics. The researcher realized it in her senior secondary and graduation class when there was less no of girl students in her mathematics class. So the researcher planned to finding out the reason behind the less interested and less participation of girls in math and its related field. She used self questionnaire for conducting the research among 80 girls of private and government students of Nawada district of Bihar state, India. The researcher finds out that Most of the students started disliking mathematics when they were in $9^{\text {th }}$ or $10^{\text {th }}$ class and making responsible herself for that. Some students claim the bad condition of teaching and learning are the main cause of less interest in mathematics. students reveal that mathematics is an interesting game, which develops our mind, create critical thinking, increase logical ability, gives the energy to think and understand, refresh the mind, play with mind etc. but they are interested in their favorite or elected subjects(biology, social science etc) more than mathematics. Some students realize mathematics is hard and tough subject so, they can't choose mathematics in their senior secondary class. At last Most of the students recommend that every field in which girls have interest is best for them for making career. No particular field is divided for particular sex.

\section{REFERENCES}

Amelink, C. T. (2012). Female Interest in Mathematics. Apply Research to Practice.

Frenzel, A. C., Pekrun, R. and Goetz, T. (2007). Girls and mathematics - A "hopeless" issue? A control-value approach to gender differences in emotions towards mathematics. European Journal of Psychology of Education, 12, 497-514. https://doi.org/10.1007/BF03173468

Hu, J. C. (Nov 4, 2016). Why Are There So Few Women Mathematicians? The Atlantic.

Nuthanap, G. (2007). Gender Analysis of Academic Achievement among High School Students. Dharwad, India.

Stanic, L. H. (Jan, 1988). Race, Sex, Socioeconomic Status, and Mathematics. Journal for Research in Mathematics Education, 19(1), 26-43. https:// doi.org/10.2307/749109 